\title{
ENTENDIMENTOS DE PROFESSORAS UNIDOCENTES SOBRE O TEMA SAÚDE: APONTAMENTOS FRENTE À FORMAÇÃO INICIAL/CONTINUADA, PLANOS DE ESTUDOS E PLANEJAMENTOS DOCENTES EM UMA ESCOLA ESTADUAL DO RS
}

\author{
Rhenan Ferraz de Jesus, Instituto Federal Farroupilha - Alegrete, Rio Grande do Sul - \\ Brasil \\ Rosalvo Luis Sawitzki, Universidade Federal de Santa Maria - UFSM, Santa Maria, Rio \\ Grande do Sul - Brasil
}

\section{RESUMO}

Neste estudo pretendeu-se estabelecer um paralelo entre os planos de estudos de uma escola e os planejamentos unidocentes nos Anos Inicias do Ensino Fundamental, buscando averiguar se os professores trabalham, em seus planejamentos, a temática Saúde sob a ótica do que está previsto nesses planos de estudos. Sendo assim, constituiu-se uma investigação descritiva qualitativa, caracterizada como um estudo de caso, dividida em quatro etapas: 1) levantamento bibliográfico; 2) autorização Coordenadoria Regional de Educação (CRE) e consentimento da Direção da escola e professores; 3) análise documental; e 4) aplicação de questionário. Utilizou-se uma técnica de organização de dados e análise descritiva. Pelos resultados das análises, foi possível identificar a existência de conteúdos relacionados à Saúde nos Anos Iniciais, sendo notório que esses documentos trazem uma abordagem e entendimento por Saúde de uma maneira ampla e abrangente, ainda que, predominantemente, ao enfoque biológico. Entende-se haver a necessidade de uma reformulação nos planejamentos de ensino dos professores e dos planos de estudos da escola para trabalhar a Saúde em uma perspectiva mais abrangente e educativa, considerando todos os aspectos do contexto do aluno.

Palavras-Chave: Saúde; Planejamento e plano de estudos; Professores; Escola; Formação docente.

\section{UNDERSTANDINGS OF TEACHERS UNIDOCENTES ABOUT HEALTH'S THEME: NOTES ABOUT THE INITIAL/CONTINUED FORMATION, STUDY PLANS AND TEACHING PLANS AT A STATE SCHOOL OF RS}

\begin{abstract}
In this study it was intended to establish a parallel between the study plans of a school and teacher's education plans teaching from first to fourth grades of the Early Years of Elementary Education, seeking to establish whether the teachers work, in their plannings, the Health's theme from of the perspective of what is foreseen in these plans studies.

Conexões: revista da Faculdade de Educação Física da UNICAMP, Campinas, v. 13, n. 4, p. 49-78, out./dez. 2015. ISSN: 1983-9030.
\end{abstract}


Therefore, it was constituted a qualitative descriptive research, featured as a case study, divided into four steps: 1) literature study; 2) the authorization of the Regional Coordination Education (RCE) and consent's Director of the school and of the teachers; 3) documental analysis; and 4) questionnaire application. It was used data's organization technique and descriptive analysis. From the results of the analyzes, it was possible to identify the existence of health-related content in the Early Years, it is becoming clear that these documents bring an approach and understanding for Health a broad and comprehensive way, although predominantly to the biological approach. It is understood there be a need for a reformulation in the teacher's education plans and study plans of a school to work on a more comprehensive health and educational perspective, considering all aspects of the student's context.

Key-Words: Health; Planning and study plans; Teachers; School; Teacher’s training.

\title{
ENTENDIMIENTOS DE MAESTROS UNIDOCENTES SOBRE EL TEMA SALUD: ALGUNAS NOTAS DE ENCONTRO LA FORMACIÓN INICIAL/FORMACIÓN CONTINUA, PLANES DE LOS ESTUDIOS Y PLANES LECCIONES EN UNA ESCUELA ESTATALES DE RS
}

\begin{abstract}
RESUMEN
Este estudio establece un paralelo entre los planes de estudios de una escuela y planes de lecciones de los maestros de primero a cuarto grado en los primeros años de Educación Primaria, que objetiva comprobar si los maestros trabajan, en sus planificaciones, el tema de la Salud sobre la perspectiva de lo que es previsto en estos planes estudios. Formada una investigación cualitativa descriptiva, un estudio de caso, dividido en cuatro pasos: 1) estudio bibliográfico; 2) autorización de la Coordinación Regional de Educación (CRE) y consentimiento del Director de la escuela y maestros; 3) análisis de documentos; y 4) aplicación de lo cuestionario. Fue utilizado la técnica de organización de los datos y el análisis descriptivo. Fue posible identificar la existencia de contenidos destinados en la Salud en los primeros años, siendo evidente que estos documentos traer un acercamiento y comprensión de la Salud de una manera amplia, aunque predominantemente hacia un enfoque biológico. Se entiende que es necesario una reforma en los planes de lecciones de los maestros y los planes de estudios de la escuela, para trabajar el tema de la Salud en una perspectiva más amplia y educativa, de considerar todos los aspectos del contexto del estudiante.
\end{abstract}

Palabras-Clave: Salud; Planificación y planes de los estudios; Maestros; Escuela; La formación del profesorado.

Conexões: revista da Faculdade de Educação Física da UNICAMP, Campinas, v. 13, n. 4, p. 49-78, out./dez. 2015. ISSN: 1983-9030. 


\section{INTRODUÇÃO}

Esta investigação emergiu a partir de uma inquietação acadêmica, a qual é um recorte de uma monografia apresentada no Curso de Especialização em Educação Física Escolar (EFE) pela Universidade Federal de Santa Maria (UFSM). O presente estudo vem trazer em tela a temática Saúde dentro do contexto escolar, em caso particular nos Anos Iniciais do Ensino Fundamental de uma escola estadual gaúcha, a partir de análise documental dos planos de estudos desta escola e dos planejamentos unidocentes, os quais atuam nessa fase da escolarização formal, buscando entender como essa temática é/foi desenvolvida na formação inicial e continuada dos professores.

Segundo Bracht, ${ }^{1}$ os Parâmetros Curriculares Nacionais (PCNs), no que se refere ao ambiente escolar e em função de algumas mudanças inerentes à própria sociedade, consideram a saúde como um tema transversal. Essa perspectiva de transversalidade partiu do Ministério da Educação e do Desporto, ${ }^{2}$ onde foi criado o referencial curricular nacional para a educação fundamental, no qual a Saúde é tida como um tema transversal a ser trabalhado e assumido com responsabilidade no projeto de toda a escola. Tão logo, a proposta do Ministério da Educação (MEC) esboça a saúde como uma das peças-chave para a articulação entre as diferentes atividades e disciplinas escolares, bem como entre esta e a sociedade.

Apesar de ser um tema de grande estima para o âmbito escolar, até o presente momento, o termo Saúde continua provocando muita discussão e reflexão quanto ao seu conceito. Aliás, desde quando a escola passou a ser encarada como um espaço primordial e integrador de conhecimentos que são pertinentes entre a educação e a saúde. Nesse espaço, os conceitos elaborados quanto ao que vem a ser saúde devem ser objeto de cuidadosa reflexão, para que se possa perceber e atuar de forma coerente no sentido de contribuir efetivamente na formação dos educandos. ${ }^{3}$ Ademais, Darido ${ }^{4: 29}$ ressalta que o conceito de saúde apresenta limitações quando se pretende defini-lo de maneira estanque e conclusiva. Para essa autora, isso porque, quando se fala em saúde, não podemos deixar de considerar os fatores que influenciam esse conceito, como: meio ambiente, aspectos biológicos, socioeconômicos, culturais, afetivos e psicológicos. 
Nessa perspectiva, é possível perceber a educação como um potencial gerador de saúde, onde a escola é vista como um lugar seguro e saudável, facilitando a adoção de comportamentos mais saudáveis, encontrando-se numa posição ideal para promover e manter a saúde da comunidade educativa e da comunidade envolvente. ${ }^{5}$ Para tal, Valença Neto et al. ${ }^{6}$ alegam que existe o reconhecimento do ambiente escolar como ideal para traçar discussões que levam a refletir a respeito da importância de se tornar saudável, bem como à adoção, também, de um estilo profícuo à saúde.

Com isso, Darido ${ }^{4}$ faz questão de sugerir que o tema Saúde seja inserido dentro das escolas, afinal, conhecer, discutir, conscientizar e instrumentalizar os alunos é um dos objetivos educacionais. Da mesma maneira, acredita-se que, nesse profícuo espaço, uma das formas de contribuir para o processo de transformação da sociedade, sem abrir mão dos conteúdos convencionais, conforme Busquets et al., ${ }^{7}$ é por meio da inclusão dos Temas Transversais na estrutura curricular da escola. De acordo com Almeida, ${ }^{8}$ os temas transversais vêm ao encontro da função da atual escola, a qual é de contribuir para a formação dos alunos como cidadãos integrados e atuantes na sociedade em que vivem. Concomitantemente, percebe-se que esta relevante temática (Saúde) tenciona reflexões sobre o ambiente escolar, uma vez considerado como um espaço ideal para disseminar informações sobre si e do que está em torno do sujeito, bem como das relações existentes ali, ainda mais quando esse tema faz parte da programação de um conjunto dos conteúdos escolares para o primeiro ciclo da Educação Fundamental.

Pronuncia-se isso, pois inúmeros questionamentos surgem sobre a abordagem desse tema nas escolas. No caso particular deste trabalho, vislumbra-se, mais precisamente, sobre a existência dessa temática na proposta curricular das escolas públicas estaduais, já que trabalhar este tema nos Anos Iniciais do Ensino Fundamental da Educação Básica seria um desafio para a Educação e para a área da Educação Física. Em específico, destacando um questionamento relativo à área da Educação Física nos Anos Iniciais, resgatado por Florence e Araújo, ${ }^{9}$ que apontam a Educação Física, após a vigência da nova Lei de Diretrizes e Bases da Educação Nacional (LDBEN) - Lei nº 9.394/96, como componente curricular obrigatório na Educação Básica, mas não sendo obrigatória a sua realização por

Conexões: revista da Faculdade de Educação Física da UNICAMP, Campinas, v. 13, n. 4, p. 49-78, out./dez. 2015. ISSN: 1983-9030. 
um profissional devidamente habilitado em Licenciatura na Educação Física nas fases da educação infantil e anos iniciais.

As escolas geralmente contam com apenas um professor para cada turma nos anos inicias, chamado de "unidocente” ou "polivalente”, sendo que o estado do Rio Grande do Sul prevê gratificações nos vencimentos dos professores que exercem a unidocência (Lei Estadual $n^{0}$ 10.576/1995), incentivando este tipo de atuação. Sendo assim, nesta investigação, elegeu-se como foco de atenção essa etapa de ensino e os profissionais da educação que nela atuam. São vários os motivos que levaram a escolha dessa temática em estudo. Um destes se reflete na compreensão de que a saúde, os fatores que a influenciam e determinam podem ser entendidos de diversas formas, o que acaba acarretando distintas abordagens para o seu ensino em sala de aula. ${ }^{10}$ Da mesma forma que os resultados de uma investigação, ${ }^{11}$ relatando que, em muitas situações, os professores não têm sido preparados para abordar essa temática na escola e, conforme Nahas ${ }^{12}$ e Guedes, ${ }^{3}$ a saúde é um dos temas pouco explorados pelos docentes.

Além das diretrizes curriculares alocarem um entendimento de que o ensino de saúde tem sido um grande desafio, e centrado basicamente na transmissão de informações sobre como as pessoas adoecem, os ciclos de doenças, os sintomas e as formas de profilaxia, ${ }^{13}$ acreditase que estas informações não são suficientes para que os alunos desenvolvam atitudes de vida saudável, ${ }^{2}$ muito menos que só a informação possa garantir mudanças de comportamentos. ${ }^{14}$ No caso particular deste estudo, esse ensejo prevaleceu após uma análise dos documentos norteadores de uma escola estadual investigada, pois, nesta instituição de ensino, os planos de estudos apontam que há um enfoque prescritivo e memorizador referente ao tema saúde, o qual tange, predominantemente, o aspecto biológico. ${ }^{15}$ Assim sendo, isso foi um alavanque para compreender o que se perpassa nessa realidade escolar, visto que a partir da década de 1980 surgiram novas propostas para superar os modelos tradicionais de ensino.

Como apontam os PCNs, ${ }^{2,} 16$ a escola, sozinha, não levará os alunos a adquirirem saúde, podendo e devendo, entretanto, fornecer elementos que os capacitem para uma vida saudável. Além do mais, há um entendimento que o currículo da educação deve estar Conexões: revista da Faculdade de Educação Física da UNICAMP, Campinas, v. 13, n. 4, p. 49-78, out./dez. 2015. ISSN: 1983-9030. 
voltado para a formação de um professor que possa trabalhar com as questões referentes à saúde de forma adequada. ${ }^{17}$ Por isso, embora a instituição educacional não tenha a tarefa precípua de dar atendimento a problemas de saúde dos alunos, existe uma obrigação inerente à profissão de ensinar, no sentido de promover o bem-estar das crianças e criar melhores condições para a sua aprendizagem. ${ }^{18}$

Em vista do que foi exposto, e sabendo da existência de conteúdos relacionados à Saúde nos Anos Iniciais do Ensino Fundamental, pretendeu-se estabelecer um paralelo entre essa proposta curricular da escola investigada e os planejamentos dos profissionais da educação que atuam nesse nível de ensino, buscando averiguar se estes(as) educadores(as) trabalham, em seus planejamentos, a temática Saúde sob a ótica do que está previsto nesses planos de estudos. Ainda, buscando investigar se essa temática é/foi desenvolvida na formação inicial e continuada dos professores, em vista à realidade de uma escola estadual de um município da fronteira oeste do Rio Grande do Sul.

\section{METODOLOGIA}

\section{Delineamento da Pesquisa e Procedimentos}

Essa investigação se caracteriza como um estudo de caso, também considerada uma pesquisa descritiva qualitativa, ${ }^{19}$ constituída em quatro etapas. Para a primeira etapa do estudo, realizou-se um levantamento bibliográfico, sendo feitas consultas em sites de produção científica como em revistas e periódicos eletrônicos, trabalhos monográficos, dissertações e teses, a livros publicados que tratassem o eixo temático 'Saúde’. Em um segundo momento, entrou-se em contato com a equipe diretiva de uma escola estadual no município de Manoel Viana/RS, com o intuito de solicitar autorização para, por conseguinte, viabilizar a realização desta pesquisa. Quando obtida esta permissão, estabeleceu-se contato com as professoras unidocentes (informação verbal) ${ }^{1}$ para que as mesmas pudessem participar e permitir a próxima fase da pesquisa, a qual se tratava, segundo Lüdke e André, ${ }^{19}$ de uma análise documental sobre os planejamentos unidocentes

\footnotetext{
${ }^{1}$ Nesta investigação, contou-se apenas com a participação de professoras unidocentes, as quais pertencem ao sexo feminino, e as quais são os únicos profissionais da educação que lecionam e atuam nos Anos Iniciais desta escola estadual.

Conexões: revista da Faculdade de Educação Física da UNICAMP, Campinas, v. 13, n. 4, p. 49-78, out./dez. 2015. ISSN: 1983-9030.
} 
e, ainda, sob o plano de estudos - proposta curricular que norteia os conteúdos a serem trabalhados nesta escola.

Ressalta-se que as professoras aceitaram participar desta investigação de maneira voluntária e por conveniência, onde foi mantido o anonimato delas, para isso, as mesmas assinaram um Termo de Consentimento Livre e Esclarecido (TCLE), no qual foi explicitado o consentimento dos participantes, de forma escrita, contendo todas as informações necessárias, em linguagem clara e objetiva, de fácil entendimento, para o mais completo esclarecimento sobre a pesquisa a qual se propôs, respeitando os critérios éticos da pesquisa conforme os termos da Resolução 466/2012 do Conselho Nacional de Saúde. Ressalta-se que este trabalho foi aprovado pelo Comitê de Ética em Pesquisa da Universidade Federal de Santa Maria (protocolo de nº 5346/2015).

Depois disso, após o aceite de participação das unidocentes, passou-se para a quarta fase do estudo: a aplicação de um questionário com questões abertas ${ }^{20}$ - procurando investigar se a temática saúde é/foi desenvolvida na formação inicial e continuada das professoras. $\mathrm{O}$ período para a coleta dos dados fora compreendido na primeira quinzena do mês de dezembro de 2013. O questionário foi elaborado pelos pesquisadores com duas questões, sendo uma delas bem específica sobre o tema Saúde, conforme dispostas no Quadro 1. O mesmo foi entregue às professoras quando convidadas a participar do estudo, logo, na medida em que as professoras respondiam os questionamentos, estes foram entregues devidamente preenchidos aos pesquisadores responsáveis.

Quadro 1 - Questões sobre a formação das professoras e trabalho do tema saúde na formação inicial/continuada unidocente

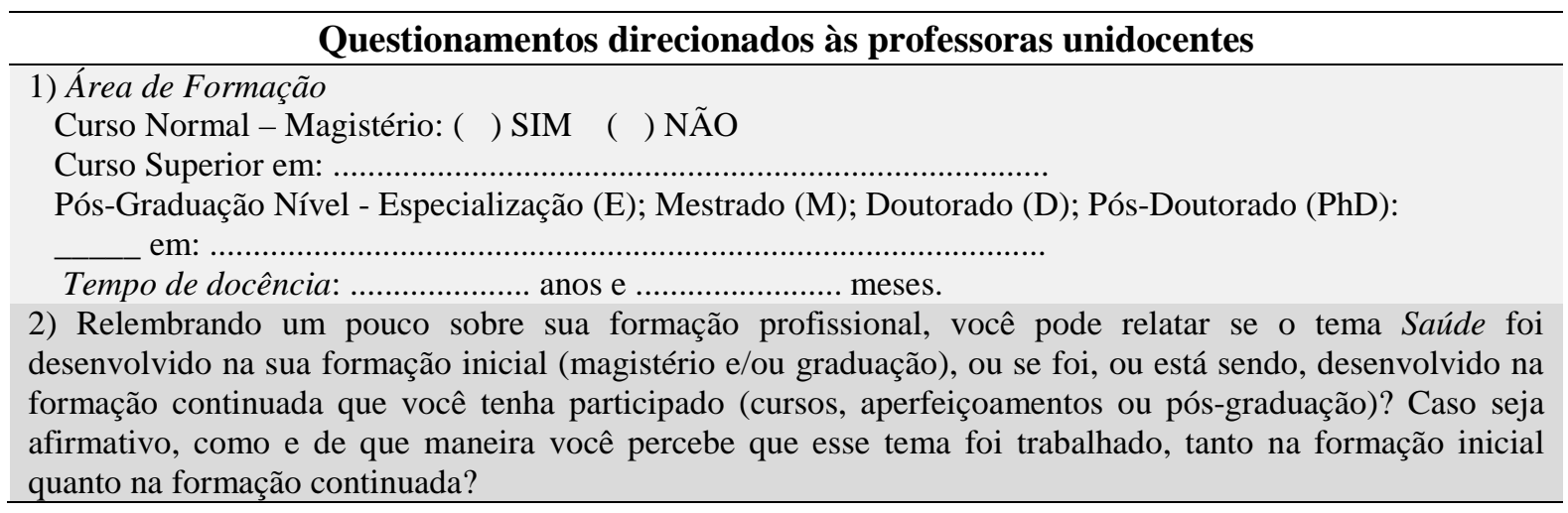

Conexões: revista da Faculdade de Educação Física da UNICAMP, Campinas, v. 13, n. 4, p. 49-78, out./dez. 2015. ISSN: 1983-9030. 


\section{Amostra e Coleta dos Dados}

Participaram deste estudo, por conveniência e voluntariamente, cinco professoras que atuam nos Anos Iniciais do Ensino Fundamental em uma escola da rede pública estadual de Manoel Viana, Rio Grande do Sul (RS). Para a fase da coleta dos dados, quando fora entrado em contato com o educandário, a Secretaria da escola e Coordenadora Pedagógica disponibilizaram cópias dos planos de estudos, constantes no Projeto Político Pedagógico (PPP) da instituição de ensino, os quais preveem os conteúdos que devem ser trabalhados nos respectivos anos escolares, divididos por componentes curriculares. Na coleta dos planejamentos unidocentes, as professoras, também, disponibilizaram seus materiais de planejamento de ensino, onde foram reproduzidas cópias dos documentos.

\section{TRATAMENTO, ANÁLISE E INTERPRETAÇÃO DOS DADOS}

Disposto desses dois elementos documentais, deu-se início à análise documental. Tão logo, para interpretação e análise dos resultados, aderiu-se uma análise descritiva para os dados numéricos, sendo os mesmos quantificados e apresentados de forma ilustrativa em gráficos. De um modo breve, aderiu-se uma análise estatística, utilizando as planilhas EXCEL 2010 para checagem automática e consistente das médias e desvio padrão das idades, bem como do tempo de atuação das unidocentes investigadas. E, para as perguntas abertas, utilizou-se uma técnica de organização de dados, além da interpretação das informações obtidas, cujos dados foram expostos em recortes dos principais relatos das professoras sobre como é/foi abordado o tema saúde em seus cursos de formação inicial/continuada.

Salienta-se que, para a apresentação dos resultados, foram indicados pseudônimos (nomes de flores) para cada uma das professoras estudadas, com a finalidade de assegurar-lhes anonimato e sigilo das declarações. A partir das questões em estudo, e para melhor elucidar os resultados obtidos, subdividiu-se em duas categorias: a "A temática Saúde na formação inicial/continuada das professoras unidocentes” e “A Saúde nos planos de estudos e planejamentos unidocentes”.

Conexões: revista da Faculdade de Educação Física da UNICAMP, Campinas, v. 13, n. 4, p. 49-78, out./dez. 2015. ISSN: 1983-9030. 


\section{RESULTADOS}

Este tópico apresenta os resultados desta investigação subdivididos nas categorias já elencadas anteriormente. Ressalta-se que este trabalho contou com a participação de cinco professoras unidocentes, de um total de seis, todas pertencentes a uma escola estadual localizada na cidade Manoel Viana, Rio Grande do Sul, o qual foi o representativo da amostra constituída na presente pesquisa.

\section{A temática Saúde na formação inicial/continuada das professoras unidocentes.}

Conforme os relatos das professoras estudadas, observou-se serem bem diversificadas as formas que a temática Saúde foi vista durante a formação inicial destas educadoras. Em relação a isso, a Professora Margarida destacou que, quando cursou o Magistério, o tema Saúde foi sempre muito bem trabalhado nas aulas de Didática. Para a Professora Bromélia, durante o Magistério, esta temática teve muita ênfase sobre a alimentação.

"[...] desde a conservação e cuidados que se deve ter com a alimentação, também a cadeia alimentar dos animais, pirâmide alimentar" (Bromélia).

A Professora Jasmim colabora em sua afirmação acrescentando.

"Na minha formação foi trabalhado mais detalhado, no magistério e na graduação, foi mais superficial. O que mais aprendi foi quando trabalhei de responsável pela merenda escolar no município, onde participei de vários cursos sobre alimentação e cursos dados na escola pela nutricionista”. (Jasmim).

Por outro lado, referente como esse mesmo tema foi trabalhado na formação inicial, a Professora Tulipa vem nos salientar.

"[...] sobre saúde foi trabalhado pouquíssimos assuntos, de forma que não nos contemplasse, empobrecendo nossos saberes” (Tulipa).

O que se pode perceber pela maioria dos relatos é que, para as professoras, que cursaram Magistério - Curso Normal, o tema saúde foi trabalhado com mais ênfase do que quando cursaram o ensino superior em Pedagogia, havendo destaque na disciplina de Didática e com enfoque na alimentação. No entanto, percebeu-se uma incoerência no discurso destas unidocentes investigadas, não sendo possível notar maiores aprofundamentos de como o 
tema saúde é ou foi tratado na formação destas unidocentes, de certo por entenderem a saúde de forma muito ampla e abrangente. Talvez, isso se justificasse pela dificuldade delas externarem seus entendimentos sobre saúde, também, possivelmente por existir uma visão limitada e restrita ao aspecto biológico, e balizada por uma educação tradicional, ou ainda, como ressalta a professora Tulipa, por esta temática ter sido pouco trabalhada em seus cursos de formação inicial.

Referente à formação continuada, notou-se em um relato de uma professora que o tema saúde vem sendo discutido e abordado de alguma forma com mais evidência.

"[...] atualmente, nos cursos de formação que tenho participado, percebo que o Tema Saúde continua sendo trabalhado, só que com mais ênfase” (Margarida).

Certamente, esse relato da Professora Margarida tem grande sentido com a realidade quando ela menciona que a saúde está sendo trabalhada com continuidade e enfaticamente, pois, acredita-se que esta seja uma das características da formação permanente, suprir uma formação anterior (inicial) onde não fora oportunizado momentos com mais ênfase no assunto tratado. Uma dessas formas contínuas de trabalho que envolva a temática saúde, conforme outro relato de uma professora unidocente, é por intermédio do Programa Saúde na Escola (PSE).

Para a Professora Rosa, dentro da formação continuada, o tema saúde foi trabalhado através do PSE. Remetendo-se à literatura para fins esclarecedores, conforme fontes do site eletrônico do Ministério da Educação do Governo Federal, é possível observar que o PSE tem por finalidade contribuir para a formação integral dos estudantes da rede pública de educação básica por meio de ações de prevenção, promoção e atenção à saúde. A partir disso, é perceptível observar que a escola se torna um lugar fundamental para disseminar a importância de educar para a saúde, bem como um espaço para discutir Saúde como um geral, em benefícios da sua própria saúde e da saúde da comunidade envolvente.

\section{A saúde nos planos de estudos e planejamentos unidocentes.}

Este tópico apresenta uma análise feita sobre os planos de estudos da escola e planejamento das professoras investigadas, as quais são pertencentes aos Anos Iniciais $\left(1^{\circ}\right.$ Conexões: revista da Faculdade de Educação Física da UNICAMP, Campinas, v. 13, n. 4, p. 49-78, out./dez. 2015. ISSN: 1983-9030. 
ao $5^{\circ}$ ano), com o intuito de averiguar se essas educadoras trabalham, em seus planejamentos, o tema Saúde paralelamente aos conteúdos desenvolvidos às suas atividades pedagógicas. Identificou-se que estes planos de estudos têm as seguintes denominações: “Sugestão de Programa do $1^{\circ}$ ano" para o primeiro ano, e "Mapeamento" para os demais anos do Ensino Fundamental. Sendo assim, para melhor elucidar os achados destes elementos, destacaram-se essas análises conforme a ordem crescente dos Anos Iniciais que se apresentaram.

Para o Plano de estudos do Primeiro ano $\left(1^{\circ}\right)$, nesse documento os temas a serem trabalhados são mencionados em tópicos, seguidos dos conteúdos específicos em cada um deles. Assim, entende-se ser relevante destacar o componente curricular, tópicos e os conteúdos que abordam o tema Saúde, de acordo com a Sugestão de Programa do $1^{\circ}$ ano. Houve destaque para o componente curricular 'Ciências', o qual teve maior aproximação à temática em estudo, sendo apresentado um recorte deste plano apenas desse componente como mostra o Quadro 2.

Quadro 2 - Recorte da Sugestão de Programa do $1^{\circ}$ ano

\begin{tabular}{cr}
\hline \multicolumn{2}{c}{ Plano de estudos previsto para o $\mathbf{1}^{\mathbf{0}}$ ano que contemple o tema Saúde } \\
\hline Componente curricular & Descrição dos conteúdos abordados \\
\hline Ciências & $\begin{array}{r}\text { Alimentos: nomes; diferenças entre alimentos de origem animal e vegetal; } \\
\text { conservação; e as refeições: desjejum, o almoço, o jantar o lanhe; }\end{array}$ \\
\hline
\end{tabular}

Fonte: Planos de estudos para os Anos Iniciais da escola investigada, adaptado pelos Autores (2014).

Quanto ao planejamento da unidocente responsável pelo $1^{\circ}$ ano, cabe salientar que esta professora utiliza, como recurso didático, alguns livros para trabalhar o tema Saúde “Porta aberta”, especificadamente, de Ciências para $1^{\circ}$ ano; "Para que serve o ar?”, "Pingo D’água” e “Alimentos saudáveis”, ambos recomendados pelo Ministério da Educação e de uso exclusivo nas salas de aulas do $1^{\circ}$ ano. Pela análise dos materiais didáticos apresentados e propostos, percebeu-se que essa unidocente apresenta trabalhar o tema saúde de uma forma ampla e conteudista baseada no livro didático, especificadamente, trabalhando com conteúdos relacionados ao conhecimento do próprio corpo e em movimento, dos cuidados com o corpo, ambiente e higiene, além de resgatar informações

Conexões: revista da Faculdade de Educação Física da UNICAMP, Campinas, v. 13, n. 4, p. 49-78, out./dez. 2015. ISSN: 1983-9030. 
sobre hábitos saudáveis, boa alimentação, e a importância do ar, água e solo, todos trabalhados sob produções textuais, leituras e confecção de cartazes.

O Plano de estudos para o segundo ano do Ensino Fundamental (Mapeamento do $2^{\circ}$ ano), também houve proximidade ao componente curricular 'Ciências', ao abordar o tema Saúde, sendo apresentado um trecho deste plano no Quadro 3.

Quadro 3 - Recorte do Mapeamento do $2^{\circ}$ ano.

\begin{tabular}{|c|c|}
\hline \multicolumn{2}{|c|}{ Plano de estudos previsto para o $2^{\circ}$ ano que contemple o tema Saúde. } \\
\hline Componente curricular & Descrição dos conteúdos abordados \\
\hline Ciências & - Higiene pessoal e escolar; trabalhar com material concreto. \\
\hline
\end{tabular}

Em relação ao planejamento unidocente do $2^{\circ}$ ano, notou-se um aprofundamento maior, além do descrito no plano de estudo para este ano, para o tratamento da temática em estudo, apesar de estar ancorado estritamente, também, no modelo biológico. Compreendese que a professora Bromélia associa o tema Saúde relacionando-o com as disciplinas de Ciências, História, Geografia, Língua Portuguesa e Matemática, mais especificadamente sobre alimentação saudável, diferentemente do que é previsto pelo Plano de estudos. Entre os recursos didáticos utilizados por esta docente está o livro “Comilão, o comilão”, da Editora Salamandra, o qual tem um intuito de levar a uma reflexão sobre alimentos saudáveis. Buscando construir conceitos, procedimentos e atitudes, entre os objetivos específicos de seu planejamento de ensino, encontrou-se.

- Ler conto, realizando antecipações de sentidos;

- Narrar oralmente o desfecho de uma história;

- Ler e produzir receitas culinárias;

- Refletir sobre as características do gênero receita culinária;

- Compreender a relação do homem e do homem com os alimentos ao longo da história;

- Conhecer os alimentos típicos da região onde vive;

- Compreender o conceito da alimentação saudável;

- Construir uma pirâmide alimentar, considerando o conceito de alimentos saudáveis. (Planejamento da Professora Bromélia).

Além do mais, segundo o seu planejamento, o componente curricular Ensino Religioso traz uma associação sobre a importância da saúde, por meio de textos, mensagens, orações e confecção de cartazes. Porém, analisando os conteúdos da disciplina de Ciências é que se 
percebeu uma abordagem mais ampla sobre saúde às demais disciplinas, mesmo com ênfase no autocuidado do corpo, como prevenção de doenças por meio da vacinação à prática regular de atividades esportivas. Essa mesma unidocente descreveu em seu planejamento para o componente ‘Ciências', o seguinte:

- Cuidar da higiene;

- cuidar da alimentação;

- respirar ar puro;

- praticar esporte;

- dormir em quarto limpo e arejado;

- combater o piolho e outros insetos nocivos;

- tomar água tratada

- cuidar dos dentes;

- ler bons livros;

- assistir bons programas de televisão;

- usar vacinas. (Planejamento da Professora Bromélia).

Frente ao Plano de estudos do $3^{\circ}$ ano, o "Mapeamento do $3^{\circ}$ ano" monstra que os conteúdos ensinados estão seccionados nas disciplinas de Português, Matemática, Ciências, Educação Física, Ensino Religioso, Educação Artística e Estudos Sociais. Pelo mapeamento deste ano investigado, foi possível perceber que algumas disciplinas abordam, de alguma maneira, o tema Saúde nos conteúdos, conforme o Quadro 4.

Quadro 4 - Recorte do Mapeamento do $3^{\circ}$ ano.

\begin{tabular}{|c|c|}
\hline \multicolumn{2}{|c|}{ Plano de estudos previsto para o $3^{\circ}$ ano que contemple o tema Saúde } \\
\hline Componente curricular & Descrição dos conteúdos abordados \\
\hline Ciências & $\begin{array}{l}\text { Hábitos de higiene pessoal e escolar; alimentação, vestuário, cuidado com os } \\
\text { dentes, conservação da saúde; combate aos piolhos; seres vivos; imunição: } \\
\text { vacinas por meio de preservação de doenças infectocontagiosa; dengue; } \\
\text { utilidades da água, indispensável a todos os seres vivos; reconhecimento e } \\
\text { importância dos vegetais na conservação da saúde; origem dos alimentos; partes } \\
\text { do corpo humano. }\end{array}$ \\
\hline Educação Física & $\begin{array}{l}\text { Coordenação (motora fina e ampla, viso-motora e espaço temporal); equilíbrio } \\
\text { (estático e dinâmico); lateralidade; percepções; sociabilidade e afetividade } \\
\text { (dentro das aptidões físicas poderão ser observadas); flexibilidade; força (usando } \\
\text { o próprio corpo); agilidade e destreza; velocidade; descontração (parcial e total); } \\
\text { ajuste postural; resistências anaeróbica (absorção do oxigênio); atividades } \\
\text { recreativas e formativas; pequenos jogos (ativos, moderados e calmos); hábitos } \\
\text { de higiene; hábitos alimentares. }\end{array}$ \\
\hline Educação Artística & Jogos Recreativos. \\
\hline
\end{tabular}

Fonte: Planos de estudos para os Anos Iniciais da escola investigada, adaptado pelos Autores (2014).

Conexões: revista da Faculdade de Educação Física da UNICAMP, Campinas, v. 13, n. 4, p. 49-78, out./dez. 2015. ISSN: 1983-9030. 
Em relação ao planejamento unidocente do $3^{\circ}$ ano, percebe-se que a professora Rosa associou o tema Saúde enfaticamente nos conteúdos de Ciências, como noções do corpo humano, hábitos alimentares, doenças, vacinas, hábitos de higiene, prevenção de doenças e conservação da própria saúde. Tudo isso, buscando trabalhar com atividades teóricas no quadro negro, e outras como pinturas de gravuras e figuras, cruzadas e confecções de cartazes. Para a prevenção de doenças, dentro do próprio planejamento, esta professora destaca que a alimentação saudável, a higiene, o lazer, a prática de esportes e o repouso nos ajudam a ter boa saúde e ajudam o nosso corpo a resistir mais as doenças como gripes, resfriados e pneumonia. Além disso, ela resgata o conceito de Saúde definido pela Organização Mundial da Saúde (OMS).

“Pois saúde é: bem estar físico, mental e social”. (Planejamento da Professora Rosa).

Ainda, esta mesma unidocente destaca algumas atitudes das pessoas para cuidar da saúde, dentro do seu planejamento.

- Dormir pelo menos 8 horas por noite;

- Escovar os dentes ao acordar, e após as refeições;

- Ter uma alimentação saudável;

- Tomar banho todos os dias;

- Praticar esportes regularmente;

- Brincar nos momentos de lazer;

- Cuidar da limpeza da casa;

- Lavar bem os alimentos;

- Tomar vacinas. (Planejamento da Professora Rosa).

Além do mais, essa unidocente relatou outros enfoques tratados com a temática Saúde, como atividades e tarefas para serem realizadas em casa, por exemplo, pesquisas sobre quais alimentos são saudáveis e não saudáveis na comunidade onde os alunos estão inseridos. Assim sendo, foi possível notar que alguns desses enfoques revelam uma dimensão procedimental de como os conteúdos são tratados, onde são empregadas atividades pelo professor que envolva a participação dos alunos, as suas experiências nas situações, as quais levam os alunos na tomada de decisões e a realização de atividades de maneira linear, buscando uma finalidade.

Em relação ao plano de estudos do $4^{\circ}$ ano, "Mapeamento do $4^{\circ}$ ano", identificou-se também os conteúdos ensinados, seccionados nas disciplinas de Português (presente o 
subitem Leitura), Matemática, Ciências, Estudos Sociais, Educação Artística e Ensino Religioso. Notou-se uma diferenciação em relacionado ao ano anterior, pois, pelo plano de estudos do $4^{\circ}$ ano, não há presença da disciplina de Educação Física. Entre as disciplinas que se percebeu o tratamento da temática Saúde no Mapeamento do $4^{\circ}$ ano, apresentando um recorte desse plano no Quadro 5, do que está previsto notoriamente para o componente curricular 'Ciências'.

Quadro 5 - Recorte do Mapeamento do $4^{\circ}$ ano.

Plano de estudos previsto para o $4^{\circ}$ ano que contemple o tema Saúde

\section{Componente curricular} higiênicos); a importância da higiene geral, escolar, corporal, da habilitação;

Ciências

\section{Descrição dos conteúdos abordados}

cuidado com os dentes; a saúde: com hábitos de alimentação e higiene (sentandose corretamente, mastigando bem os alimentos, praticando diariamente a higiene pessoal); vacinas (importância a tipos principais); principal doença infectocontagiosas [...].

Fonte: Planos de estudos para os Anos Iniciais da escola investigada, adaptado pelos Autores (2014).

Quanto ao planejamento unidocente do $4^{\circ}$ ano, conforme a professora Jasmim, em uma conversa informal, ela relatou que além de trabalhar diariamente o tema Saúde (noções de higiene, hábitos alimentares, corpo humano, as principais doenças e vacinas, etc.) com os alunos em sala de aula procurando sempre os incentivar a adotarem hábitos saudáveis às suas vidas, ainda, ela salientou que em seu planejamento diário não está registrado todas estas atividades mencionadas ao abordar esta temática. Percebeu-se isso, principalmente, sobre a disciplina de Educação Física, onde não há menção, ou qualquer associação ao tema saúde, dos conteúdos estudados no planejamento unidocente, mesmo ausente no plano de estudos e presente em seu planejamento. Mesmo assim, ela afirma abordar "saúde” nas aulas de Educação Física por meio de atividades recreativas e brincadeiras lúdicas, bem como nos momentos de lazer durante as aulas e seus intervalos. Ainda assim, pode-se observar uma restrição quanto ao conceito de saúde apresentado pelo planejamento da professora Jasmim. Ela fragmenta esse conceito em uma visão física e mental, diferentemente da apresentada pela Organização Mundial da Saúde, bem como dos demais entendimentos encontrados na literatura.

- Para conservar a saúde física é necessário: beber água limpa; tomar banho diariamente; escovar os dentes após as refeições; lavar as mãos antes das refeições; andar calçado. 
- Para conservar a saúde mental é preciso: viver em paz consigo mesmo; eliminar a raiva, o egoísmo e o ódio; dormir oito horas por dia; e ler bons livros. (Planejamento da Professora Jasmim).

A partir do que foi apontado sobre a temática Saúde, entende-se que as atividades desenvolvidas nesse ano se resumiram em recortes de jornais, pinturas de gravuras e figuras, fazeres de completar as frases, cruzadas e etc., sendo possível notar um trabalho dos conteúdos relacionados à Saúde de uma maneira ampla, restritamente biológica, podendo ser associada às dimensões conceitual (conceitos) e atitudinal (incentivo para a adoção de hábitos saudáveis).

Para o Plano de estudos do $5^{\circ}$ ano, "Mapeamento do $5^{\circ}$ ano", estão presentes as disciplinas de Português, Matemática, Ciências, Estudos Sociais e Ensino Religioso. No entanto, há um entendimento de que apenas componente curricular de Ciências aborda parcialmente o tema Saúde nos conteúdos descritos no Plano de estudos para esse ano, segundo o que mostra um recorte deste plano no Quadro 6.

Quadro 6 - Recorte do Mapeamento do $5^{\circ}$ ano

\begin{tabular}{cc}
\hline \multicolumn{2}{c}{ Plano de estudos previsto para o $5^{\mathbf{0}}$ ano que contemple o tema Saúde } \\
\hline Componente curricular & Descrição dos conteúdos abordados \\
\hline Ciências & $\begin{array}{c}\text { - água (importância, tipos, cuidados com a água contaminada, transmissão de } \\
\text { doenças); solo (importância, formação, como evitar o esgotamento do solo, o } \\
\text { solo e nossa saúde - poluição e doenças); e ar atmosférico (camadas da } \\
\text { atmosfera, características gerais do ar, o ar e a nossa saúde - poluição e doenças). }\end{array}$ \\
\hline Fonte: Planos de estudos para os Anos Iniciais da escola investigada, adaptado pelos Autores (2014).
\end{tabular}

Em relação ao Planejamento unidocente para o mesmo ano, a professora Margarida afirmou não utilizar tal recurso, denominado como diários de classe ou cadernos, que fossem conter os conteúdos a serem trabalhados no $5^{\circ}$ ano do Ensino Fundamental na escola investigada. Ainda, ela disponibilizou em um relato descrito aos pesquisadores, como o tema saúde contemplava suas atividades pedagógicas nas diversas disciplinas. Ela destacou o componente curricular 'Ciências'.

"Na disciplina de Ciências são desenvolvidos conteúdos sobre água, ar e solo. Em todos esses conteúdos é trabalhado o tema Saúde através de leituras, práticas, relatos, entrevistas, pesquisas, enquetes, palestras, minifeira de Ciências, incorporando, assim, os conhecimentos do tema saúde à vida de cada aluno”. (Relato da Professora Margarida).

Conexões: revista da Faculdade de Educação Física da UNICAMP, Campinas, v. 13, n. 4, p. 49-78, out./dez. 2015. ISSN: 1983-9030. 
Da mesma forma, essa unidocente tem um posicionamento sobre saúde.

"[...] Diariamente, procuro chamar a atenção dos alunos de maneira que eles conheçam $e$ desenvolvam hábitos e atitudes importantes para ter boa saúde e venham a interessar-se pelos cuidados do corpo e aplicar os conhecimentos científicos em benefício próprio e da coletividade, o que implica em adotar hábitos saudáveis e demonstrar posturas de respeito consigo e com as outras pessoas[...] ”. (Relato da Professora Margarida).

Sendo assim, percebeu-se que na disciplina de Ciências a temática saúde continua sendo, de alguma forma, prioritariamente abordada também para o $5^{\circ}$ ano. Além disso, a partir do discurso desta unidocente, notou-se que em suas aulas são desenvolvidas atividades que visam às dimensões conceitual (água, ar e solo - de maneira reducionista), procedimental (práticas e minifeiras de Ciências) e atitudinal (chamada da atenção dos alunos que eles conheçam e possam desenvolver hábitos e atitudes importantes à saúde) dos conteúdos a serem trabalhados na proposta pedagógica docente, onde há uma associação do tema saúde. Para tanto, embora em uma análise geral pelos planejamentos das professoras unidocentes, notou-se que a temática Saúde acaba sendo tratada genericamente como conteúdo da disciplina de Ciências por intermédio do livro didático e dos diários unidocentes (cadernos), predominantemente, na transmissão de informações como cuidado com o corpo, ambiente e higiene; hábitos alimentares; principais doenças, sintomas e as formas de profilaxia. Ainda, os planos de estudos vistos para cada ano do ensino fundamental também estão pautados nessa visão biologicista e medicalizada, sendo mais enfática no componente curricular de Ciências.

\section{DISCUSSÃO}

Diante do que foi exposto, a partir da categoria “A temática Saúde na formação inicial/continuada das professoras unidocentes", compreende-se que investigar como o tema Saúde foi proposto na formação inicial e continuada das professoras unidocentes se tornaria muito relevante, devido à importância da discussão deste tema no âmbito escolar. Colaborando com o assunto, e para poder se aproximar dessa realidade investigada, encontrou-se em uma pesquisa realizada ${ }^{21}$ que procurou analisar o currículo do curso de Pedagogia sobre o tema Educação em Saúde de uma Universidade Estadual de São Paulo, vindo a investigar qual a percepção dos estudantes desse curso sobre o tema por intermédio Conexões: revista da Faculdade de Educação Física da UNICAMP, Campinas, v. 13, n. 4, p. 49-78, out./dez. 2015. ISSN: 1983-9030. 
de respostas a um questionário. Nessa investigação, em relação ao currículo, observou-se que duas das 73 disciplinas analisadas trabalham a Educação em Saúde na escola de modo explícito. As respostas dos alunos revelaram que 65\% dos respondentes não percebem esta abordagem no currículo, porém 85\% consideram a atuação do pedagogo indispensável para o desenvolvimento desse tema no ambiente escolar. ${ }^{21}$ Nesse sentido, a preocupação que se tem aqui, vem ao encontro à afirmação de Gavidia, ${ }^{22}$ quando se tem um entendimento que pode haver um déficit na formação inicial dos professores para tratar de temas relativos à educação em saúde.

Para Bagnato, ${ }^{23}$ por exemplo, a Educação em Saúde no espaço escolar depende, em grande parte, do preparo acadêmico dos educadores. Alguns anos antes, também já evidenciava a necessidade da formação crítica de educadores para que esses soubessem articular teoria e prática, vinculadas às condições de vida da população. ${ }^{24}$ Fomentando essa discussão, considera-se necessário e fundamental que o currículo da formação do pedagogo possibilite a reflexão crítica do aluno referente a tal temática, com o objetivo de que o entendimento desse aluno no campo da Educação em Saúde ultrapasse uma concepção fragmentada, medicalizada e reducionista. ${ }^{21}$ Para isso, o professor tem que estar bem preparado, bem formado pelos cursos de graduação das universidades. A sensibilização e a formação do corpo docente têm importância fundamental para que a Educação em Saúde exista de fato e seja bem trabalhada dentro das escolas. ${ }^{21}$ Em relação à formação continuada, o próprio Ministério da Saúde propõe a necessidade de formação e qualificação docentes para a abordagem da promoção à saúde em ambiente escolar. ${ }^{25}$ Como complementam alguns autores, ${ }^{25-27}$ para o professor poder assumir sua responsabilidade de agente transformador, existe a necessidade de formação continuada. E no âmbito escolar, o PSE vem corroborar, nesse sentido, para a formação integral dos estudantes por meio de ações de promoção da saúde, de prevenção de doenças e agravos à saúde e de atenção à saúde, com vistas ao enfrentamento das vulnerabilidades que comprometem o pleno desenvolvimento de crianças e jovens da rede pública de ensino. ${ }^{28}$

Dessa forma, destaca-se que no ambiente escolar deve haver espaço para educadores e alunos discutirem questões sobre saúde, mas, para isso, é fundamental que os educadores tenham formação e conhecimento suficiente. ${ }^{11}$ Libâneo $^{29}$ acredita que os momentos de Conexões: revista da Faculdade de Educação Física da UNICAMP, Campinas, v. 13, n. 4, p. 49-78, out./dez. 2015. ISSN: 1983-9030. 
formação continuada levam os professores a uma ação reflexiva. Uma vez que após o desenvolvimento da sua prática, os professores poderão reformular as atividades para um próximo momento, repensando os pontos positivos e negativos ocorridos durante o desenrolar da aula. Desta maneira, é com grande valia que se entende a necessidade da formação continuada, pois, muitas vezes, uma formação inicial estanque não dá conta de todos os conteúdos que devem ser trabalhados com os alunos dos Anos Iniciais, justamente onde se trabalha com todas as áreas do conhecimento ao mesmo tempo na formação unidocente.

Sendo assim, é fundamental que o professor se entenda como sujeito de transformação, e busque por uma formação contínua, cursos ou até mesmo outras formas, recusando-se a aceitar que a configuração do mundo que aí está seja a única possível. ${ }^{30}$ No entanto, para Nóvoa, ${ }^{31}$ a formação não se constrói por acúmulo de cursos, mas através de tarefas de reflexividade críticas sobre os métodos e de reconstrução constante do seu fazer pedagógico.

Em relação às análises documentais dos planejamentos unidocentes, complementando essa visão de trabalhar o tema Saúde no primeiro ano do ensino fundamental, a Professora Tulipa acrescentou, em um diálogo informal, que realiza atividades que envolvem o movimento corporal (percepções do próprio corpo), segundo ela, são jogos e brincadeiras recreativas, desde a ida durante o intervalo, e no final das aulas, à pracinha de brinquedos. Sobre as noções do próprio corpo, Zancha et al. ${ }^{32: 205}$ entendem que:

Transmitir informações a respeito do funcionamento do corpo, descrever as características das doenças, bem como a divulgação de hábitos de higiene, alimentação e atividades físicas, não é suficiente para que os alunos desenvolvam atitudes de vida saudável.

Por meio do discurso dessa educadora, pode-se perceber que a respeito das aulas de recreação, não descritas no plano de estudos, parecem estar contemplando suas atividades pedagógicas, apesar se saber que apenas o movimento humano, por si só, não corresponde diretamente por “saúde”. Quiçá, essa unidocente tenha uma percepção de 'Saúde’ voltada à prática de atividades corporais (como atividades físicas) na promoção da saúde no âmbito escolar, como meio de manter-se saudável a partir dos benefícios desta prática, que implicam a prevenção e possível tratamento de doenças e agravos à saúde do praticante. Conexões: revista da Faculdade de Educação Física da UNICAMP, Campinas, v. 13, n. 4, p. 49-78, out./dez. 2015. ISSN: $1983-9030$ 
Essa visão particular sobre Saúde é possível, além de que a relação dessas atividades informais subjetivas ao planejamento unidocente estejam enraizadas em uma abordagem pedagógica que visa o desenvolvimento das habilidades motoras básicas (informação verbal), ${ }^{2}$ entre elas as habilidades locomotoras, de manipulação e de estabilização.

Darido et al. $^{33}$ e Darido e Souza Junior ${ }^{34}$ trouxeram exemplos de como ensinar os conteúdos da cultura corporal de movimento na escola a partir das três dimensões dos conteúdos (procedimental, conceitual e atitudinal), em exemplo nas aulas de Educação Física, aos alunos que necessitam sair da escola como pessoas que vivenciaram situações que possam ajudá-los a compreender esses conteúdos de forma ampla e integral. ${ }^{33-34}$ Entendendo dessa maneira, que para Betti, ${ }^{35}$ esse componente curricular para mostrar o seu papel social não pode se desvincular do seu princípio educativo: a cultura do movimento.

Nesse sentido, fazendo um paralelo entre plano de estudos e planejamento unidocente para o segundo ano do ensino fundamental, entendeu-se que a professora responsável por este ano foi coerente em traçar os objetivos da aula com o que ela trabalhou com alunos, pois foi possível perceber que o tratamento da saúde se deu de maneira paralela e transversal aos conteúdos disciplinares, destacando o aspecto metodológico a ser empregado em todas as matérias, como apontado por Gavídia apud Lomônaco ${ }^{36: 34}$ e não apenas como conteúdo interdisciplinar entre as demais áreas do conhecimento. Mesmo assim, é possível notar que alguns tópicos em seu planejamento $\left(2^{\circ}\right.$ ano $)$ remetem a outros elementos relacionados à saúde. Exemplo disso, associando-se à saúde mental, quando ela descreve "ler bons livros”, à saúde pessoal quando há descrição de “dormir em quarto limpo e arejado”, “combater o piolho e outros insetos nocivos”, “cuidar da higiene”, “cuida dos dentes” e etc. Entretanto, essa unidocente relatou que procura na prática, e na medida do possível, resgatar o que as crianças sabem sobre o assunto pautado, encontrando, também, maneiras de trabalhar a realidade do aluno de acordo com os recursos e materiais didáticos que ela dispõe, os quais se tornam necessários para poder efetivar o aprendizado discente.

\footnotetext{
${ }^{2}$ Para maiores esclarecimentos sobre esta abordagem que apresenta um conceito de saúde indiretamente, sugere-se a obra: DARIDO, S. C. Os conteúdos da educação física escolar: influências, tendências, dificuldades e possibilidades. Perspectivas em Educação Física Escolar, Niterói, v. 2, n.1 (suplemento), 2001.

Conexões: revista da Faculdade de Educação Física da UNICAMP, Campinas, v. 13, n. 4, p. 49-78, out./dez. 2015. ISSN: 1983-9030.
} 
Vindo ao encontro aos dados confrontados ao $3^{\circ}$ ano, a respeito da Educação Física e Educação Artística, segundo a professora Rosa, as atividades pedagógicas destas disciplinas se resumem, com prioridade na primeira, apenas em jogos e brincadeiras recreativas, bem como idas à pracinha de brinquedos, e momentos de lazer. Desta maneira, entende-se que esta unidocente deixa omissa a aplicabilidade e a execução do plano de estudos/planejamento unidocente no que se tratam os conteúdos programados à disciplina de Educação Física como desde a coordenação (motora fina e ampla, viso-motora e espaço temporal), equilíbrio (estático e dinâmico), lateralidade, e demais descritos no Mapeamento do $3^{\circ}$ ano. Além do mais, vindo ao encontro de outra abordagem pedagógica presente no currículo escolar, a qual vê a saúde de forma indireta e resultante do desenvolvimento dos fatores psicomotores, afetivos e cognitivos (informação verbal). ${ }^{3}$

Em relação à importância da abordagem do tema saúde em aula, Zancha et al. ${ }^{32:} 205$ vêm colaborar para essa discussão, onde eles consideram importante abordar o ensino da temática Saúde nas aulas de Educação Física escolar no intuito de promover a conscientização e a formação de hábitos saudáveis na vida dos alunos. A Educação Física nos ambientes escolares sempre foi desenvolvida como momento de aulas recreativas e práticas esportivas. ${ }^{37}$ Mesmo sendo disciplina regular integrante do projeto político pedagógico da escola, esta concepção ainda continua sendo realizada pelos alunos e por alguns professores. Guedes, ${ }^{3:} 14$ afirma ser imprescindível que as crianças e os jovens tenham acesso a informações que lhes permitam estruturar conceitos mais claros quanto ao porquê e como praticar atividade física, e não praticar atividade física pelo simples fato de praticar.

Para o $4^{\circ}$ ano do Ensino Fundamental, foi percebido que o tema saúde, também, é trabalhado na disciplina de Ciências, como informações sobre o corpo humano, hábitos de higiene (dos olhos, da pele, dos ouvidos, bocal, mental, alimentar e ambiental), saúde (visão física e mental), bem estar social, as doenças, as vacinas, prevenção (de acidentes e de doenças). Essa primeira forma de abordagem do tema saúde nas escolas é vista como

\footnotetext{
${ }^{3}$ Para maiores esclarecimentos sobre esta abordagem presente no currículo escolar, sugere-se a leitura: FERREIRA, H. S. Testes psicomotores na educação infantil - bateria psicomotora (BPM): um estudo de caso em crianças de uma escola particular. 2001. 100f. Monografia (Especialização em Psicomotricidade) Centro de Educação, Universidade Estadual do Ceará, Fortaleza, 2001.

Conexões: revista da Faculdade de Educação Física da UNICAMP, Campinas, v. 13, n. 4, p. 49-78, out./dez. 2015. ISSN: 1983-9030.
} 
uma forma de conscientizarão para uma vida mais saudável no futuro, pois a aquisição de hábitos de higiene pessoal tem início na infância, destacando-se a importância de sua prática sistemática. ${ }^{38}$ As experiências de fazer junto com a criança os procedimentos passíveis de execução no ambiente escolar, a forma de lavagem das mãos ou de que forma se escova dos dentes, tendo um significado importante na aprendizagem. ${ }^{38}$ Exemplificando, alguns autores ${ }^{39}, 40$ compreendem que a educação em saúde por visar ao indivíduo, ensina regras na escola e pauta-se o conhecimento em saúde como consciência individual. Aparecendo com o predomínio do autocuidado, onde os indivíduos devem aprender a cuidar de si e a ser vigilantes de suas próprias atitudes.

A partir disso, percebe-se que é em Ciências que o tema Saúde vem sido tratado, confirmando ainda que pouco tem sido feito para romper com a tendência de restringir essa abordagem aos aspectos informativos e exclusivamente biológicos, aonde a temática saúde vem sendo prioritariamente abordada nesta disciplina. ${ }^{13,16,41}$ Mesmo assim, o conceito de saúde percebido por essa unidocente apresentou um caráter mais centrado no aspecto biológico e reducionista (conceitual), ainda distante de uma proposta que prevê uma compreensão da saúde que contemple as três dimensões do conteúdo, a saber, nas atividades pedagógicas docentes: conceitual, atitudinal e procedimental.

Em relação ao $5^{\circ}$ ano, não foram apresentadas relações tão distintas (plano de estudos e planejamento unidocente), no entanto, apresentaram semelhanças quanto ao aspecto biológico ao se referir sobre o tema saúde. Em vista disso, entende-se que a educação para a saúde abordada em um sentido exclusivamente biológico e higienista inibe o domínio e o encorajamento de atitudes favoráveis à própria saúde, não permitindo que novos conhecimentos sejam incorporados de forma integrada e duradoura em direção a autoindependência em decisões quanto à adoção de um estilo de vida saudável. ${ }^{3}$

Uma situação muito interessante que surgiu neste trabalho foi a questão da não exigência do planejamento dos professores unidocentes desta escola, onde a Coordenadoria responsável e Direção da escola, de certa maneira, não exigem com veemência tal registro a estas educadoras. Pode-se perceber isso em conversas informais com duas das professoras estudadas, que ofertam alguns elementos extras do objeto investigado, Conexões: revista da Faculdade de Educação Física da UNICAMP, Campinas, v. 13, n. 4, p. 49-78, out./dez. 2015. ISSN: 1983-9030. 
buscando compreender o seu todo. Pelo relato da professora Margarida, a mesma afirmou que não faz registros dos planejamentos de ensino em cadernos, ou diários como ainda denominam as professoras. Segundo ela, desconsiderando a $10^{\mathrm{a}} \mathrm{CRE} / \mathrm{RS}$ e Direção da escola, pelo motivo:

"o planejamento está na minha cabeça, ainda mais porque com tantos anos de docência, eles não exigem este caderno”. (Professora Margarida).

Ressalta-se, aqui, a opinião desta unidocente, onde o enunciado destacado sobre a exigência do planejamento é considerado apenas um posicionamento desta professora, assim, isso não deve ser generalizado como um único entendimento entre todas as professoras investigadas.

Além do mais, a professora Jasmim, ao contrário do que foi apontado pela professora Margarida, externa que a Coordenadoria responsável pela escola e a Equipe Diretiva, não por exigências, mas esses órgãos não são rigorosos com devidos registros no caderno do planejamento docente, mas, segundo o que ela afirmou, em virtude da falta de tempo, ela acaba não detalhando especificadamente em seu caderno diário todos os conteúdos trabalhados em aula. Assim sendo, notou-se que a professora Jasmim trabalha os conteúdos em sala de aula, no entanto, não os registra adequadamente por falta de tempo e, segundo ela, por ter outras coisas a fazer que inviabilizam esse processo, os quais não foram citadas e identificadas. Para as outras três professoras, percebeu-se que duas utilizam livros didáticos como recursos para seus planejamentos de aula e outra utiliza registros em cadernos (diários), como as datas, especificando os componentes curriculares, os conteúdos e as atividades a serem desenvolvidas.

Para tal, já que os propósitos da escola se realizam por meio dos conteúdos, é necessário que a instituição escolar supere uma concepção fracionada e reducionista, ultrapassando o distanciamento entre o conhecimento escolar e o cotidiano dos alunos de uma maneira crítica e construtiva para a vida dos alunados. ${ }^{42}$ Assim sendo, entende-se que o papel mais importante quanto ao ensino do tema saúde vem caber ao professor, o qual facilita as discussões por meio da formulação de estratégias para o trabalho escolar, ${ }^{2}$ que deve assumir explicitamente a responsabilidade de educar para a saúde. ${ }^{43}$

Conexões: revista da Faculdade de Educação Física da UNICAMP, Campinas, v. 13, n. 4, p. 49-78, out./dez. 2015. ISSN: 1983-9030. 


\section{CONSIDERAÇÕES FINAIS}

Quanto ao questionamento se essa temática (Saúde) é e/ou foi desenvolvida na formação inicial e continuada dessas educadoras, observou-se serem bem diversificadas as formas que a temática Saúde foi vista durante a formação inicial dessas professoras; para a formação continuada, observou-se a manifestação minimizada de professoras relatando que o tema saúde vem sido abordado com mais evidencia a partir de cursos de formação permanente.

Pelos resultados encontrados, por meio de análises dos planos de estudos da escola e os planejamentos unidocentes investigados, foi possível identificar a existência de conteúdos relacionados à Saúde nos Anos Iniciais, sendo notório que esses documentos trazem uma abordagem e entendimento por Saúde de uma maneira ampla e abrangente, ainda que, predominantemente, voltada ao enfoque biológico. É preocupante esta visão tradicional em documentos educativos, visto que a partir da década de 1980 surgiram novas propostas para superar os modelos clássicos de ensino, visando atender as atuais problemáticas existentes nas diferentes realidades que perpassam o contexto escolar.

Com base nisso, percebeu-se que os planos de estudos vistos para cada ano do ensino fundamental da escola estudada devem ser revistos e revisados quanto à abordagem do tema Saúde, juntamente com o Projeto Político-Pedagógico da mesma, podendo ser levado a toda comunidade escolar para maiores discussões, oportunizando espaços para trocas de experiências e debate da própria realidade e contexto escolar. Assim, podendo efetivar a participação e colaboração de todos no processo de elaboração e lapidação em conjunto de um documento norteador mais condizente com a educação escolar, voltada à prática social e de grande importância para a formação do educando.

Nesse sentido, compreende-se, também, que há a necessidade de uma reformulação dos planos de trabalhos do professor unidocente para se trabalhar a Saúde em uma perspectiva mais ampla e educativa, desde que considerem todos os aspectos do contexto do aluno, como os já mencionados por vários autores referenciados (biológico, psicológico, social, econômico, profissional, espiritual, cultural, etc.). Pois, prima-se envolver o tema Saúde em uma perspectiva educacional que possa estar contribuindo de maneira construtiva ao Conexões: revista da Faculdade de Educação Física da UNICAMP, Campinas, v. 13, n. 4, p. 49-78, out./dez. 2015. ISSN: 1983-9030. 
processo educativo dos estudantes. Conclui-se que essa aproximação (traçar um paralelo entre documentos da escola e dos professores) com a realidade escolar faz refletir, ainda mais, como o tema saúde é tratado (ou como deveria ser tratado) no ambiente escolar, para atender a necessidade educativa que a realidade escolar demanda.

\section{REFERÊNCIAS}

${ }^{1}$ BRACHT, V. Saber e fazer pedagógicos: acerca da legitimidade da educação física como componente curricular. In: CAPARRÓZ, F. E. (Org.). Educação Física escolar: política, investigação e intervenção. Vitória: Proteoria, 2001. p. 67-79.

${ }^{2}$ BRASIL. Ministério da Educação e Cultura. Secretaria de Educação Fundamental. Parâmetros curriculares nacionais: terceiro e quatro ciclos do ensino fundamental: temas transversais. Brasília, 1998. 436p.

${ }^{3}$ GUEDES, D. P. Educação para saúde mediante programas de educação física escolar. Motriz, Rio Claro, v. 5, n. 1, jun. 1999.

${ }^{4}$ DARIDO, S. C. (Org.). Educação física e temas transversais na escola. Campinas: Papirus, 2012.

${ }^{5}$ SCHULLER, T. et al. The benefits of learning: the impact of education on health, family life and social capital. London: Routledge Falmer, 2003.

${ }^{6}$ VALENÇA NETO, P. F. et al. Estágio supervisionado I: educando para além do conceito saúde. EFDeportes.com: revista digital, Buenos Aires, ano 16, n. 164, 2012. Disponível em: $\quad$ http://www.efdeportes.com/efd164/estagio-supervisionado-educando-conceitosaude.htm. Acesso em: 10 out. 2013.

${ }^{7}$ BUSQUETS, M. D. et al. Temas transversais em educação: bases para uma formação integral. 6. ed. São Paulo: Ática, 2000.

Conexões: revista da Faculdade de Educação Física da UNICAMP, Campinas, v. 13, n. 4, p. 49-78, out./dez. 2015. ISSN: 1983-9030. 
${ }^{8}$ ALMEIDA, T. J. B. Abordagem dos temas transversais nas aulas de ciências do ensino fundamental, no distrito de Arembepe, município de Camaçari-BA. Candombá: revista virtual, Bahia, v. 2, n. 1, p. 1-13, jan./jun. 2006.

${ }^{9}$ FLORENCE, R. B. P.; ARAÚJO, P. F. de. A Educação física frente a LDB 9394/96. EFDeportes.com: revista digital, Buenos Aires, ano 10, n. 86, 2005. Disponível em: http://www.efdeportes.com/efd86/ldb.htm. Acesso em: 26 out. 2013.

${ }^{10}$ MONTEIRO, P. H. N. A saúde nos livros didáticos no Brasil: concepções e tendências nos anos iniciais do ensino fundamental. 2012. 210 f. Tese (Doutorado em Educação) Faculdade de Educação, Universidade de São Paulo, São Paulo, 2012.

${ }^{11}$ COSTA, S.; GOMES, P. H. M.; ZANCUL, M. S. Educação em saúde na escola na concepção de professores de ciências e de biologia. In: ENCONTRO NACIONAL DE PESQUISA EM EDUCAÇÃO EM CIÊNCIAS, 7., 2011, Florianópolis. Anais... Florianópolis: $\quad 2012 . \quad$ ABRAPEC, Disponível em: www.nutes.ufrj.br/abrapec/viiienpec/resumos/R0922-1.pdf. Acesso em: 18 set. 2013.

${ }^{12}$ NAHAS, M. Educação para a aptidão física e saúde: justificativa e sugestões para implementação nos programas de Educação Física. Revista Brasileira de Ciência e Movimento, Brasília, v. 8, n. 3, 1997.

${ }^{13}$ BRASIL. MINISTÉRIO DA EDUCAÇÃO E CULTURA. Secretaria de Educação Fundamental. Parâmetros Curriculares Nacionais: temas transversais: meio ambiente e saúde. 2. ed. Rio de Janeiro: DP\&A, 2000. 128p.

${ }^{14}$ NAHAS, M. V. Atividade física, saúde e qualidade de vida: conceito e sugestões para um estilo de vida ativo. 4. ed. Londrina: Midiograf, 2006.

${ }^{15}$ JESUS, R. F. Entendimentos de professores unidocentes sobre o tema saúde no contexto escolar: um estudo de caso nos Anos Inicias de uma escola estadual. 2014. 69 f. 
Trabalho de Conclusão de Curso (Especialização em Educação Física Escolar) Universidade Federal de Santa Maria, Santa Maria, 2014.

${ }^{16}$ BRASIL. Ministério da Educação e Cultura. Secretaria de Educação Fundamental. Parâmetros Curriculares Nacionais: terceiro e quatro ciclos do ensino fundamental: ciências naturais. Brasília, 1998. 138p. Disponível em: <http://portal.mec.gov.br/seb/arquivos/pdf/ciencias.pdf> . Acesso em: 17 dez. 2013.

${ }^{17}$ LOMÔNACO, A. F. S. Concepções de saúde e cotidiano escolar: o viés do saber e da prática. In: REUNIÃO ANUAL DA ASSOCIAÇÃO NACIONAL DE PÓSGRADUAÇÃO E PESQUISA EM EDUCAÇÃO, 27., 2004, Caxambu. Anais... Caxambu: ANPED, 2004. Disponível em: http://www.anped.org.br/reunioes/27/gt06/t063.pdf. Acesso em: 03 dez. 2013.

${ }^{18}$ ANDERSON, C. L.; CRESWELL, W. H. School health practice. $6^{\text {th }}$ ed. St. Louis: C.V. Mosby, 1976.

${ }^{19}$ LÜDKE, M.; ANDRÉ, M. E. D. A. Pesquisa em educação: abordagens qualitativas. 8. ed. São Paulo: EPU, 2004.

${ }^{20}$ GIL, A. C. Métodos e técnicas de pesquisa social. 6. ed. São Paulo: Atlas, 2010.

${ }^{21}$ LEONELLO, V. M.; L’ABBATE, S. Educação em saúde na escola: uma abordagem o currículo e da percepção de alunos de graduação em pedagogia. Interface: comunicação, saúde, educação, Botucatu, v. 10, n. 19, p. 149-66, jan./jun. 2006.

${ }^{22}$ GAVIDIA, V. El profesorado ante la educación y promoción de la salud en la escuela. Didáctica de las Ciencias Experimentales y Sociales, v. 23, p. 171-180, 2009.

${ }^{23}$ BAGNATO, M. H. S. A contribuição educativa dos programas de saúde na $5^{\text {a }}$ série do $1^{\circ}$ grau. 1987. Dissertação (Mestrado) - Universidade Federal de São Carlos, São Carlos, 1987.

Conexões: revista da Faculdade de Educação Física da UNICAMP, Campinas, v. 13, n. 4, p. 49-78, out./dez. 2015. ISSN: 1983-9030. 
${ }^{24}$ SILVA, J. I. A educação do educador: a formação do educador em debate. Caderno Cedes, Campinas, v. 1, n. 2, p. 39-42, 1983.

${ }^{25}$ BRASIL. Ministério da Educação. O projeto saúde nas escolas: texto de apoio. Brasília, 2002.

${ }^{26}$ NONOSE, E. R.; BRAGA, T. M. Formação do professor para atuar com saúde/doença na Escola. In: CONGRESSO NACIONAL DE EDUCAÇÃO/III CONGRESSO ÍBEROAMERICANO SOBRE VIOLÊNCIAS NAS ESCOLAS, 7., 2008, Curitiba. Anais... Curitiba: Pontifícia Universidade Católica do Paraná, 2008. p. 3656-3667. Disponível em: http://www.pucpr.br/eventos/educere/educere2008/anais/pdf/407_455.pdf. Acesso em: 17 dez. 2013.

${ }^{27}$ DINIZ, M. C. P.; OLIVEIRA, T. C.; SCHALL, V. T. Saúde como compreensão de vida: avaliação para inovação na educação em saúde para o ensino fundamental. Ensaio Pesquisa em Educação em Ciências, Belo Horizonte, v. 12, p. 119-144, 2010.

Disponível em: http://www.portal.fae.ufmg.br/seer/index.php/ensaio/article/viewArticle/264

${ }^{28}$ BRASIL. Ministério da Educação. Secretaria de Educação Continuada, Alfabetização e Diversidade. Programa saúde nas escolas. Brasília, 2007. Disponível em: http://portal.mec.gov.br/index.php?option=com_content\&id=14578\%3Aprograma-saudenas-escolas\&Itemid=817. Acesso em: 16 dez. 2013.

${ }^{29}$ LIBÂNEO, J. C. Adeus professor, adeus professora? novas exigências educacionais e profissões docente. São Paulo: Cortez, 1998.

${ }^{30}$ VASCONCELLOS, C. S. Para onde vai o professor? resgate do professor como sujeito de transformação. 10. ed. São Paulo: Libertad, 2003.

${ }^{31}$ NÓVOA, A. formação de professores e profissão docente. In: NÓVOA, A. (Org.). Os professores e a sua formação. Lisboa: Dom Quixote, 1992.

Conexões: revista da Faculdade de Educação Física da UNICAMP, Campinas, v. 13, n. 4, p. 49-78, out./dez. 2015. ISSN: 1983-9030. 
${ }^{32}$ ZANCHA, D. et al. Conhecimento dos professores de educação física escolar sobre a abordagem saúde renovada e a temática saúde. Conexões, Campinas, v. 11, n. 1, p. 204217, jan./mar. 2013.

${ }^{33}$ DARIDO, S. C. et al. A educação física, a formação do cidadão e os parâmetros curriculares nacionais. Revista Paulista de Educação Física, São Paulo, v. 15, n. 1, p. 1732, 2001.

${ }^{34}$ DARIDO, S. C.; SOUZA JÚNIOR, O. Refletindo sobre a tematização do futebol na educação física escolar. Motriz, Rio Claro, v. 16, n. 4, p. 920-930, 2010.

${ }^{35}$ BETTI, M. Educação física e sociedade. São Paulo: Movimento, 1991.

${ }^{36}$ LOMÔNACO, A. F. S. Concepções, ensino e práticas de saúde no cotidiano escolar: a educação para a saúde em escolas públicas de Uberlândia (MG). 2004. 166 f. Dissertação (Mestrado em Educação) - Faculdade de Educação, Universidade Federal de Uberlândia, Uberlândia, 2004.

${ }^{37}$ REIS. P. F. Desafios da educação física escolar no ensino médio frente à sociedade contemporânea. $2005 . \quad$ Disponível em: http://www.educadores.diaadia.pr.gov.br/arquivos/File/2010/artigos_teses/EDUCACAO_F ISICA/PANORAMADAEDUCACAOFISICAESCOLARNOENSINOMEDIO.pdf. Acesso em: 16 dez. 2013.

${ }^{38}$ BRASIL. Ministério da Educação e Cultura. Secretaria de Educação Fundamental. Parâmetros Curriculares Nacionais: meio ambiente e saúde. Brasília, 1997. 128p.

${ }^{39}$ TORRES, A. L. A saúde bucal coletiva sob a ótica de professores da rede estadual de ensino de São Paulo. 2002. Dissertação (Mestrado), Faculdade de Saúde Pública, Universidade de São Paulo, 2002.

Conexões: revista da Faculdade de Educação Física da UNICAMP, Campinas, v. 13, n. 4, p. 49-78, out./dez. 2015. ISSN: 1983-9030. 
${ }^{40}$ CECCIM, R. B. Saúde e doença: reflexão para a educação da saúde. In: MEYER, D. E. E. Saúde e sexualidade na escola. Porto Alegre: Mediação, 2006. p. 37-50.

${ }^{41}$ SILVEIRA, G. T. Escola promotora de saúde: quem sabe faz a hora! 2000. Tese (Doutorado) - Faculdade de Saúde Pública, Universidade de São Paulo, São Paulo, 2000.

${ }^{42}$ BRASIL. Ministério da Educação e Cultura. Secretaria de Educação Fundamental. Parâmetros curriculares nacionais: primeiro e segundo ciclos do ensino fundamental: tema transversal saúde. Brasília, 1998.

${ }^{43}$ FOCESI, E. Educação em saúde na escola. O papel do professor. Revista Brasileira Saúde do Escolar, C v. 1, n. 2, p. 4-8, 1990.

${ }^{44}$ LOUREIRO, C. F. A educação em saúde na formação do educador. Revista Brasileira de Saúde Escolar, Campinas, v. 4, n. 3/4, p. 10-13, 1996.

${ }^{45}$ LOUREIRO, C. F. A problemática de saúde da criança no Brasil: desafios para uma prática educativa. Revista Brasileira de Saúde Escolar, Campinas, v. 4, n. 1/2, p. 17-20. 1996.

Recebido em: 09 abr. 2015

Aceito em:11 out. 2015

Contato: rhenan.ferraz@hotmail.com

Conexões: revista da Faculdade de Educação Física da UNICAMP, Campinas, v. 13, n. 4, p. 49-78, out./dez. 2015. ISSN: 1983-9030. 